\title{
London gears up for road congestion charge
}

\section{David Adam}

The streets of London were once said to be paved with gold, but modern-day prospectors are more likely to find them filled with traffic. In a bid to lose London's tag as one of the most congested places in Europe, its local authority is about to start charging people who want to drive into the city centre.

Whether or not the plan succeeds, it will provide the most important test so far of the scientific models used to design such schemes, and transport researchers are itching to see what happens.

"London is essentially being turned into a big laboratory," says David Milne, a traffic researcher at the University of Leeds. "Road pricing schemes have been kicked around in modelling terms in the United Kingdom since the 1960s, but we haven't any real evidence of how people respond."

From 17 February, people wishing to drive into central London during the day will have to pay a $\mathfrak{E} 5$ (US\$8) fee. The move is intended to force an extra 20,000 daily commuters onto public transport. Cameras will register the number-plate of every vehicle entering a 13-square-kilometre central zone.

If the models prove accurate, city-centre congestion should fall by up to $30 \%$, say those running the $£ 200$-million scheme. London is not the first city to introduce such a toll, but transport experts say that the scheme, which is run by Transport for London, is the largest and most significant of its kind.

Traffic flow in the models is estimated by considering the amount of road space, and how many people want to use that space. If the models have a weak spot, it is likely to be the latter estimate, say transport researchers. Commuters have been interviewed about how they will react to the charge, and the success of the scheme could rest on whether people behave as they said they would.

"Theory and reality can be miles apart," warns a member of the working group that designed the scheme who did not want to be identified. Commuters will be swayed by the actions of those around them, for example, and emptier roads could even tempt bus and train users to get back behind the wheel instead.

Traffic flow around the edges of the charging zone is another area of uncertainty. Traffic levels in these areas could rise as drivers who don't want to pay the charge spill onto other routes. Milne says that traffic could increase as far away as the M25, the already-packed motorway that circles London some 30 kilometres out. But Transport for London points out that the working group's models predict that traffic in these areas will increase by $6 \%$ at most, and that

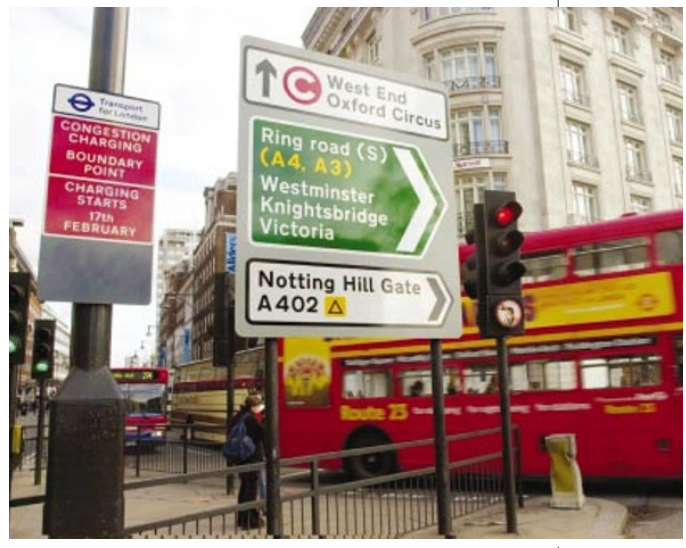

London's congestion charge is intended to force 20,000 commuters to switch to public transport.

levels there are lower anyway.

Transport for London has already announced a programme to monitor both of these areas, along with other effects of the congestion charge. The first results, based on follow-up interviews, vehicle-counting and measurements of average journey times, will be published in six months' time, although natural fluctuations in traffic levels mean that it may be years before solid conclusions can be drawn.

www.cclondon.com

\section{Long-lost wave report sinks asteroid impact theory}

\section{Rex Dalton, San Diego}

A forgotten report on ocean waves generated by nuclear explosions has surfaced, forcing researchers to rethink their theories on asteroid impacts.

The Handbook of Explosion-Generated Water Waves was completed in 1968 at the request of the US Office of Naval Research by William Van Dorn of the Scripps Institution of Oceanography in La Jolla,

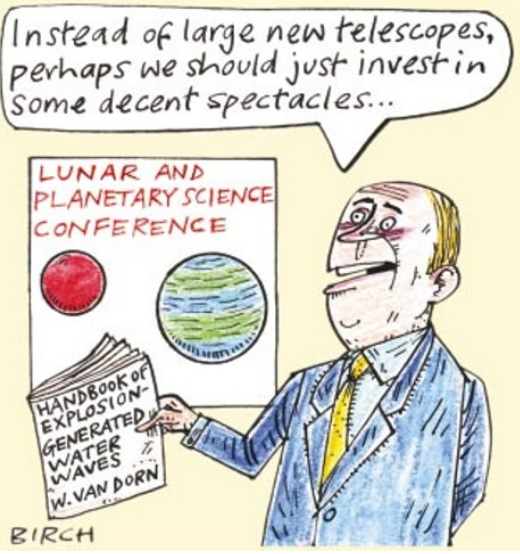

California. But it was not entered into an academic library catalogue until March 2002, when Scripps' library did so as part of a project to record old technical reports.

Since the report was written, planetary scientists have investigated the potential effect of small asteroids - particularly those with diameters of 100-500 metres landing in the ocean, and have concluded that the resulting tsunamis could devastate regions over 20 kilometres inland.

But new analyses of Van Dorn's highly technical report on waves produced by nuclear explosions, which takes account of factors such as the absorption of wave energy by continental coastal shelves, indicate that tsunami damage would be limited to immediate coastal areas.

Jay Melosh, a planetary scientist at the University of Arizona in Tucson, tracked down the report last year. He plans to talk at the Lunar and Planetary Science Conference in League City, Texas, next month about his own analyses that predict limited inland damage from asteroid-generated waves. "It appears the defence community has already determined that explosion-generated waves are neither a serious threat nor a promising weapon," writes Melosh in his abstract.

Such risk assessments are extremely important as governments consider the costs of telescopes or satellites needed to conduct asteroid surveys. Scientists agree that the impact of an asteroid larger than $1 \mathrm{~km}$ in diameter would be catastrophic, but there is much debate over the risk from smaller ones. If Earth is under threat only from larger asteroids, then equipment and research costs will be much lower than if scientists also have to look out for numerous smaller objects.

The US government is funding the development of the Panoramic Survey Telescope and Rapid Response System and the Large Synoptic Survey Telescope, whose brief includes surveys of asteroids of various sizes. The latter telescope is expected to cost around \$200 million.

A NASA task force is to complete a report in the spring on the risk from smaller asteroids. "It is fortunate this very important report has come out now," says Steve Chesley, a planetary scientist at NASA's Jet Propulsion Laboratory in Pasadena, California, and a member of the task force. 